\title{
SAÚDE DO IDOSO NAS INSTITUIÇÕES DE LONGA PERMANÊNCIA FRENTE A PANDEMIA DO CORONAVIRUS
}

Amanda Thiesen Bielinski; Universidade Luterana do Brasil - Gravataí; amandathiesenb@gmail.com Rosana Sabina Augustin da Silva; Universidade Luterana do Brasil - Gravataí; enfermagem.augustin@ gmail.com

Caroline Otto Vargas; Universidade Luterana do Brasil - Gravataí; carol-otto@hotmail.com Juliana Nunes Alves; Universidade Luterana do Brasil - Gravataí; ju.nunesa@gmail.com Priscila Carvalho Fogaça; Universidade Luterana do Brasil - Gravataí; prizinhacf@gmail.com

\section{RESUMO}

Introdução: A COVID-19 trata-se de uma doença infecciosa causada pelo novo coronavírus, onde os idosos e os portadores de doenças crônicas caracterizam o grupo de risco para doença, devido a letalidade e agravamento serem mais observados nesta população, portanto, pode-se reconhecer que as Instituições de Longa permanência para idosos (ILPI) são locais vulneráveis ao vírus, necessitando de um olhar atento e cuidados especiais para prevenção da doença. Objetivo: Compreender os cuidados para prevenção da contaminação pelo coronavírus nas ILPI's. Métodos: Revisão integrativa, através dos Decs escolhidos foram analisados as publicações nas bases de dados Lilacs, Medline e Scielo, a coleta ocorreu no mês de agosto de 2020, respondendo à questão norteadora: Como as produções cientificas nacionais contribuem para o conhecimento dos cuidados para prevenção do coronavírus nas ILPI's? Resultados: Dentre os materiais encontrados, quatro artigos se encaixaram nos critérios de inclusão, estes mostram como principais cuidados o monitoramento dos sintomas nos residentes e funcionários, uso correto dos EPI's pelos funcionários, uso da máscara pelos residentes em áreas comuns, higienização das mãos, etiqueta respiratória, redução de aglomeração em áreas comuns, isolamento dos residentes sintomáticos em quarto exclusivo, e também o desafio de buscar alternativas humanizadas para redução de visitas, como a realização de encontros remotos com familiares. Conclusão: Estes cuidados se tornam necessários para que a propagação da doença nas ILPI's não ocorra, e para isso se faz necessária a criação de protocolos, e também a promoção de capacitações e a conscientização dos envolvidos sobre o risco da doença aos residentes.

Palavras-chave: Instituição de longa permanência para idosos; Infecções por coronavirus; Saúde do idoso. 